\title{
Verification of the combined sewage system simulation model based on the example of the city of Głogów
}

\author{
Ireneusz Nowogoński ${ }^{1, *}$, and Ewa Ogiołda ${ }^{1}$ \\ ${ }^{1}$ University of Zielona Góra, Faculty of Civil Engineering, Architectural and Environmental \\ Engineering, 65-417 Zielona Góra, Poland
}

\begin{abstract}
Using SWMM 5.1 (Storm Water Management Model) software, a model of sewage system functioning in Głogów was developed. It was calibrated based on the results of field studies from the years 201114 , while the properness of its activity was verified for the results of measurements carried out during the period 1998-2000. The verification of the model showed acceptable discrepancies between the measured and simulated values of channel depth. Factors which caused differences were indicated and, on the basis of this, conclusions pertaining to further studies were formulated.
\end{abstract}

\section{Introduction}

The issue of using computer models to enable the simulation of the operating conditions of storm drainage or a combined sewage system during the course of a rainfall event is one of the more important issues which may be encountered by users of sewage systems in the near future. All works connected with the modernization of the system ought to be preceded by studies and an assessment of its day-to-day functioning. The introduction of properly calibrated theoretical models has become a necessity, above all from the technical point of view (analysis of expansion in the system, the possibility of connecting additional catchments, carrying out trenchless renovation). The work makes use of experience gained at the phase of implementing a model of the combined sewage system in Głogów. The realized studies resulted from the need to verify the number of storm water outflow activations over the course of a year.

\section{Materials and methodology}

Głogów - a city in eastern Poland in Lower Silesia Province - is located on the Oder River, with the number of inhabitants exceeding 68 thousand. The sewage system in Głogów is mainly realized as a combined system. The progressive sealing of the catchment and uncontrolled development of the sewage network in connection with the more and more frequently occurring weather anomalies has caused streets and squares to be regularly

\footnotetext{
*Corresponding author: i.nowogonski@iiis.uz.zgora.pl.
} 
flooded with sewage, as well as the flooding of residential buildings. Works aimed at solving this problem have been carried out for many years now. One of the main tasks was to develop a simulation model of the combined sewage system enabling the analysis of potential solutions and their current, as well as future influence on the sewage system.

The other purpose for developing the model was the implementation of a solution enabling the amount of occurrences of storm water outflows to the Oder River to be verified. Binding regulations allow for the storm water outflow to be activated 10 times within the course of a year. Information on this topic can be based on a constant monitoring system of the depth of runoff in the storm water drain or in the overflow crests. It is also possible to apply a calibrated simulation model using rain gauge data. The model also serves as a tool enabling the verification of the amount of times storm water was discharged into the Oder River after disassembling the measurement system in channels.

On the basis of the gathered data, a model was developed based on [3]:

- nodes - 499 nodes and 4 outlets;

- segments - 504 channel segments;

- rainfall data - $6(+1)$;

- rainfall catchments - 370 catchments;

- number of overflow structures - 4.

The model was calibrated based on the results of field studies carried out from 1 September 2011 to the end of September 2014, using standard calibration parameters [4]. The measurements covered the runoff depth within the overflow crests in three storm overflow structures, as well as the depth and intensity of flows in the inlet and outlet overflow channels. Six rain measurement stations were located within the area of the city according to the scheme presented in Figure 1.

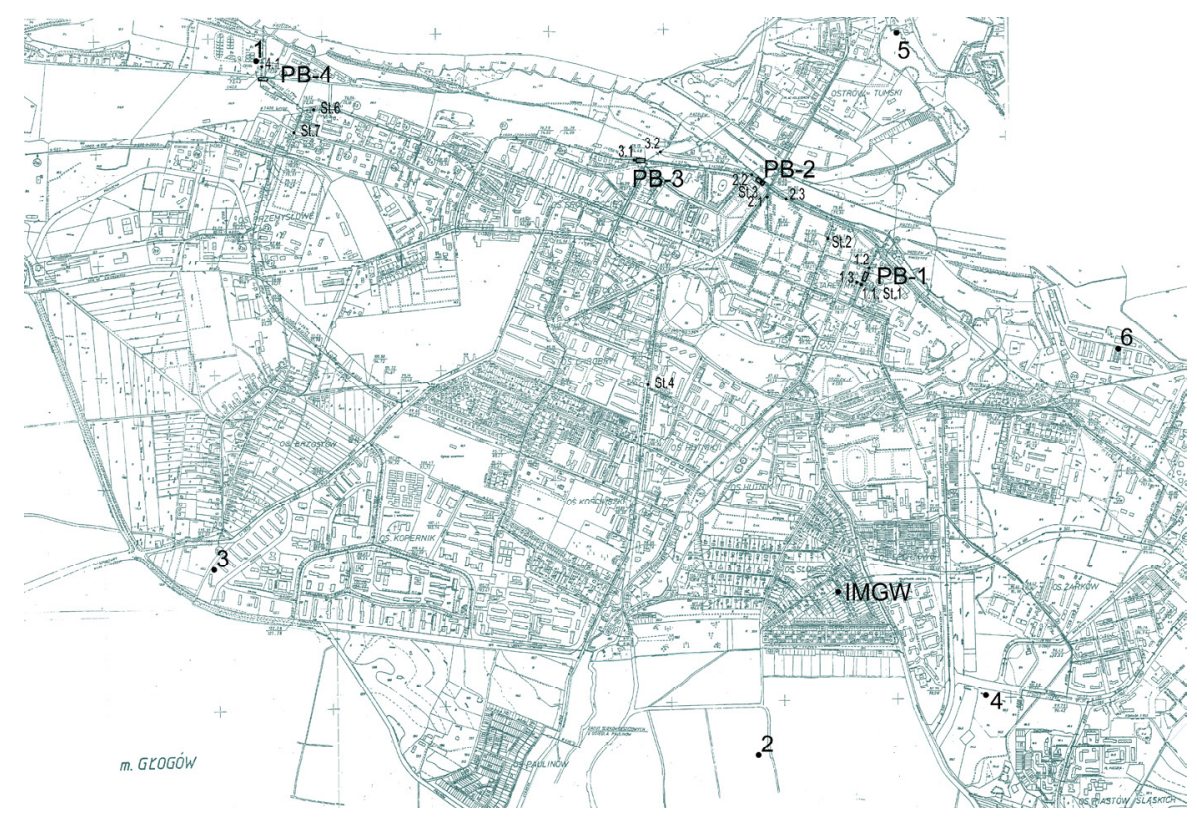

Fig. 1. Location of rain gauges and measurement stations in the area of the city: PB-1-4 - overflow structures; St.1-7 - measurement stations in the period 1998-2000; IMGW - weather station in the period 1998-2000; 1.1-4.1 - measurement stations in the period 2011-2014; 1-6 - rain gauge in the period 2011-2014 [1,2].

In the current state, the model is useful in the period upon completing field studies, under the condition of the ongoing introduction of changes introduced to the system 
(connecting additional rainwater catchments, the emergence of additional sources of sanitary wastewater, modernization of networks of channels, etc.). Another issue assumed by the team developing the model is the verification of the usefulness of the model in regards to archival events, under the assumption of possessing a limited scope of information (data from a single rain gauge operated by the Institute of Meteorology and Water Management - IMGW).

The proper functioning of the model was verified using the results of studies carried out in Głogów in the years 1998-2000 by the Institute of Environmental Engineering (University of Zielona Góra). Archival research was carried out at the stage of modernizing the sewage treatment plant in Głogów. It served, among others, to verify the capacity of the retention tank located directly before the treatment plant, enabling sewage containing outflows from the first run-off wave from the surface of the catchment to be contained. The studies were realized by the measurement of the runoff levels (depths) in channels using limnigraphs in six selected gauging sections. Meteorological data were registered at the Institute of Meteorology and Water Management (Instytut Meteorologii i Gospodarki Wodnej - IMGW) weather station. The location of the measurement stations has been presented in Fig. 1. The developed model was subjected to corrections involving the exclusion of catchments created after the year 2000 .

Table 1 presents the simplified characteristics of rainfalls in the years 1998-2000 and 2012-2014 in the form of maximum hourly rainfalls in the summer months. Data gathered by IMGW at the weather station in Głogów (1998-2000) as well as data collected using a network of rain gauges implemented by the water and sewage service company (Przedsiębiorstwo Wodociągów i Kanalizacji - PWiK) in Głogów (2012-2014) have been presented. For the measurement period 2012-2014, due to the significant differences, the smallest and highest rainfall totals noted in the presented months have been compiled. The results from the measurements at IMGW in Głogów have not been included seeing as how, during the measurement period, the object was transferred from Letnia Street to the area of the water treatment plant nearby Rain Measurement Station 1 (Figure 1).

Table 1. Maximum hourly total in the month - the summer months of 1998-2000 and 2012-2014.

\begin{tabular}{|l|c|c|c|c|c|c|}
\hline & 1998 & 1999 & 2000 & 2012 & 2013 & 2014 \\
\hline May & 9.3 & 3.7 & 5.7 & $3.3-9.1$ & $3.6-6.7$ & $9.5-22.9$ \\
\hline June & 9.1 & 14.5 & 19.2 & $10.4-13.2$ & $6.3-8.7$ & $4.6-14.8$ \\
\hline July & 4.6 & 6.2 & 5.8 & $12.5-27.3$ & $26.0-36.3$ & $6.3-23.6$ \\
\hline August & 3.9 & 3.4 & 9.9 & $5.1-11.3$ & $7.8-10.1$ & $17.3-30.3$ \\
\hline
\end{tabular}

The analysis of the gathered data made it possible to confirm the occurrence of comparable amounts of monthly and daily totals. In the years 2012-2014, on the other hand, significantly higher maximum hourly as well as daily precipitation totals were observed as compared to 1998-2000 (up to twice as high). The inconsistency of the catchment coverage with rainfall indicates the necessity of accounting for the variability of rainfall in space and time even for cities with a relatively small area. In the case of Głogów, the area lying within the borders of the city is just under $36 \mathrm{~km}^{2}$, half of which is serviced by independent stormwater drainage systems, including from the Głogów Copper Smelter site.

\section{Results and discussion}

Verification of the model based on archival data was performed by comparing the measured and simulated flow rate of runoff in the channels. A review of the registered limnigraphic data made it possible to choose 9 measurement days with registered readings for at least two measurement points (with the exception of 22.05.2000 - data were registered only for 
Site No. 6). Selected days with rainfalls have been characterized in Table 2. Daily rainfall totals noted by the recorder as well as weather station observer have been presented. The maximum 10-minute and hourly rainfall totals were also included in the compilation.

Table 2. Characteristics of phenomena used for the verification of the model.

\begin{tabular}{|c|c|c|c|c|}
\hline & $\begin{array}{c}\text { Daily rainfall } \\
\text { total }[\mathrm{mm}]\end{array}$ & $\begin{array}{c}\text { Daily rainfall } \\
\text { total (observer) } \\
{[\mathrm{mm}]}\end{array}$ & $\begin{array}{c}\text { Maximum } \\
\text { hourly total } \\
{[\mathrm{mm}]}\end{array}$ & $\begin{array}{c}\text { Maximum 10- } \\
\text { minute total } \\
{[\mathrm{mm}]}\end{array}$ \\
\hline 01.11 .1998 & 8.11 & 11.9 & 2.3 & 0.7 \\
\hline 08.05 .1999 & 10.9 & 10.9 & 3.7 & 1.0 \\
\hline 18.06 .1999 & 12.2 & 12.2 & 3.1 & 1.1 \\
\hline 14.07 .1999 & 3.6 & 3.8 & 2.3 & 1.8 \\
\hline 21.07 .1999 & 6.2 & 5.9 & 6.2 & 3.3 \\
\hline 27.08 .1999 & 4.0 & 4.2 & 3.4 & 2.4 \\
\hline 14.10 .1999 & 3.9 & 6.2 & 2.4 & 1.6 \\
\hline 22.05 .2000 & 12.5 & 12.4 & 1.7 & 0.6 \\
\hline 29.07 .2000 & 7.8 & 9.9 & 5.8 & 2.5 \\
\hline
\end{tabular}

For assessing the quality of the simulation models, classical statistical measures are recommended for comparing the results of calculations of runoff with the results of measurements (Table 3):

- relative residual error (RRE);

- Pearson's correlation coefficient (R);

- Special RS correlation coefficient

Table 3. Classification of the quality of the model based on the values of selected indicators

(Kotowski 2015; Skotnicki, Słowiński 2009).

\begin{tabular}{|c|c|c|}
\hline \multirow{2}{*}{ Category of model } & \multicolumn{2}{|c|}{ Indicators and ranges of data } \\
\cline { 2 - 3 } & R, RS [-] & RRE [\%] \\
\hline Very good & $1.00-0.99$ & $0-3$ \\
\hline Good & $0.99-0.95$ & $3-6$ \\
\hline Average & $0.95-0.90$ & $6-10$ \\
\hline Unsatisfactory & $0.90-0.85$ & $10-25$ \\
\hline
\end{tabular}

Assessment of the usefulness of the model was carried out based on the following criteria:

- relative error of estimating the maximum flow rate of runoff in gauging section of channel;

- relative error of estimating the volume of runoff flowing through the gauging section;

- relative residual error RRE estimated as [5]:

$$
R R E=\frac{\sqrt{\sum_{i=1}^{n}\left(Q_{p, i}-Q_{o, i}\right)^{2}}}{\sum_{i=1}^{n} Q_{o, i}}
$$

where:

Q - calculated flow rate;

$\mathrm{Q}_{\mathrm{p}}$ - measured flow rate.

The analysis covered 23 runoff periods connected with 9 rainfall events with an intensity of 1.7 to $6.2 \mathrm{~mm} / \mathrm{h}$. In the case of the relative error in relation to the maximum flow rate, an error of under $10 \%$ was obtained in 4 cases, an error within the range of 10 to 
$25 \%$ - in 9 cases, and an error higher than $25 \%$ - in 10 cases. In the case of the relative error in regards to the total runoff volume, an error of under $10 \%$ was obtained in 5 cases, an error within the range of 10 to $25 \%$ - in 12 cases, and over $25 \%$ - in 6 cases (Table 4).

In the case of relative residual error, a very good result was obtained in 2 cases, with a good result also noted in 2; in 9 cases the result was assessed as average, whereas in 8 unsatisfactory. Only for two cases did the results not fall within the range of quality classification (Table 5).

A slight majority of the analysed rainfall events provided acceptable results classified as average, good or very good in regard to residual error. The maximum values of flow rate cannot be considered acceptable in the majority of cases. Exemplary results have been presented in Figs. 2, 3, 4 and 5. A graphic representation of the measured and simulated runoff depth in the channel is presented in the figures.

Table 4. Relative estimation error of maximum runoff flow rate in channel and runoff volume.

\begin{tabular}{|c|c|c|c|c|c|c|c|c|}
\hline \multirow{2}{*}{$\begin{array}{c}\text { Date of } \\
\text { occurrence }\end{array}$} & \multicolumn{2}{|c|}{ Measurement Pt. 1 } & \multicolumn{2}{c|}{ Measurement Pt. 4 } & \multicolumn{2}{c|}{ Measurement Pt. 6 } & \multicolumn{2}{c|}{ Measurement Pt. 7 } \\
\cline { 2 - 9 } & $\mathrm{Q}$ & $\mathrm{V}$ & $\mathrm{Q}$ & $\mathrm{V}$ & $\mathrm{Q}$ & $\mathrm{V}$ & $\mathrm{Q}$ & $\mathrm{V}$ \\
\hline 01.11 .1998 & - & - & 37.6 & 13.1 & 26.0 & 20.1 & - & - \\
\hline 08.05 .1999 & - & - & - & - & 23.7 & 37.1 & 47.9 & 8.2 \\
\hline 18.06 .1999 & 23.5 & 43.9 & 39.1 & 18.9 & 9.9 & 38.7 & 50.4 & 16.4 \\
\hline 14.07 .1999 & - & - & 15.4 & 13.9 & 14.5 & 16.8 & 16.6 & 10.7 \\
\hline 21.07 .1999 & - & - & 30.5 & 5.6 & 11.8 & $\begin{array}{c}31.4 \\
(15.1)\end{array}$ & 36.3 & 12.5 \\
\hline 27.08 .1999 & 23.1 & 3.5 & 3.0 & 19.9 & 12.9 & $\begin{array}{c}30.9 \\
(1.8)\end{array}$ & 53.6 & 11.2 \\
\hline 14.10 .1999 & 6.0 & 3.4 & 33.8 & 29.3 & - & - & - & - \\
\hline 22.05 .2000 & - & - & - & - & 23.0 & 12.0 & - & - \\
\hline 29.07 .2000 & - & - & 31.8 & 2.0 & 6.7 & 16.8 & - & - \\
\hline
\end{tabular}

Table 5. Relative residual error (RRE).

\begin{tabular}{|c|c|c|c|c|}
\hline & $\begin{array}{c}\text { Measurement } \\
\text { Pt. 1 }\end{array}$ & $\begin{array}{c}\text { Measurement } \\
\text { Pt. 4 }\end{array}$ & $\begin{array}{c}\text { Measurement } \\
\text { Pt. 6 }\end{array}$ & $\begin{array}{c}\text { Measurement } \\
\text { Pt. 7 }\end{array}$ \\
\hline 01.11 .1998 & - & 8.7 & 6.9 & - \\
\hline 08.05 .1999 & - & - & 9.8 & 19.8 \\
\hline 18.06 .1999 & 10.8 & 7.9 & 7.2 & 17.2 \\
\hline 14.07 .1999 & - & 7.2 & 4.7 & 8.6 \\
\hline 21.07 .1999 & - & 25.1 & 10.4 & 1.8 \\
\hline 27.08 .1999 & 7.3 & 11.8 & 11.4 & 27.5 \\
\hline 14.10 .1999 & 2.1 & 16.0 & - & - \\
\hline 22.05 .2000 & - & - & 8.9 & - \\
\hline 29.07 .2000 & - & 13.0 & 5.6 & - \\
\hline
\end{tabular}

The observable differences between the obtained results of measurements and results obtained as a result of simulations can be partially explained by:

- the lack of detailed rainfall data; the model was developed accounting for differences in the course of the event in different regions of the city; verification using data from a single rain gauge;

- the low accuracy of the measurement of runoff depth using a limnigraph, falling within declared ranges. 


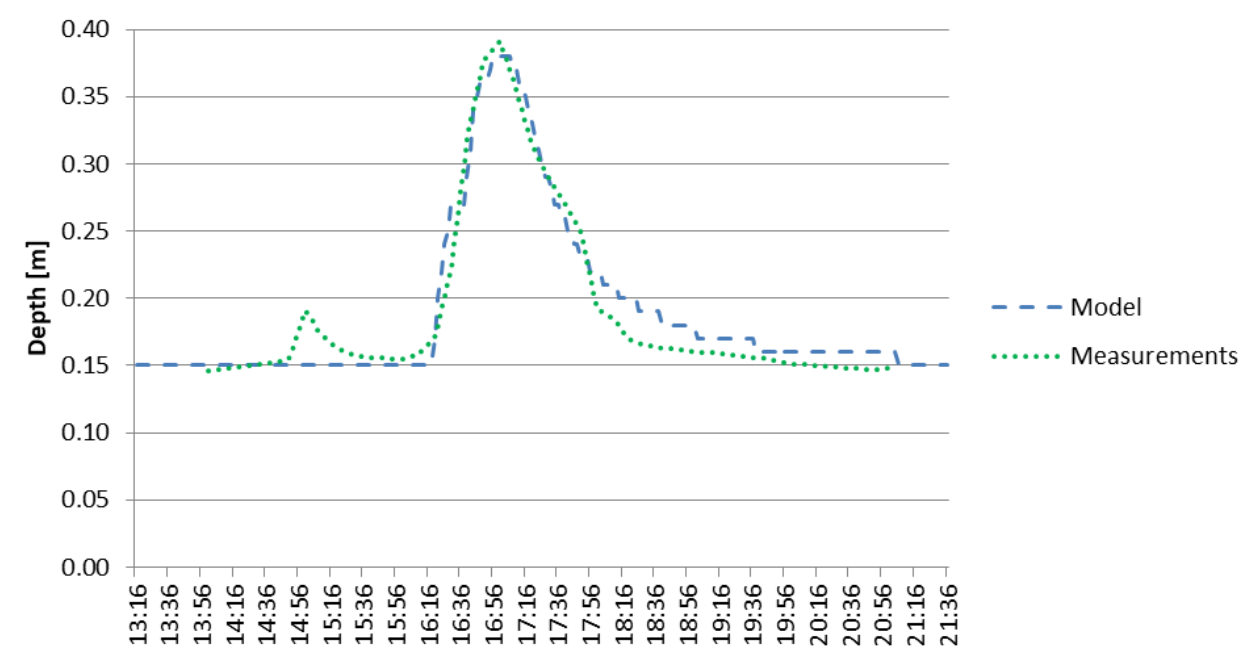

Fig. 2. Runoff depth in channel - 14.10.1999 - Measurement Point No. 1.

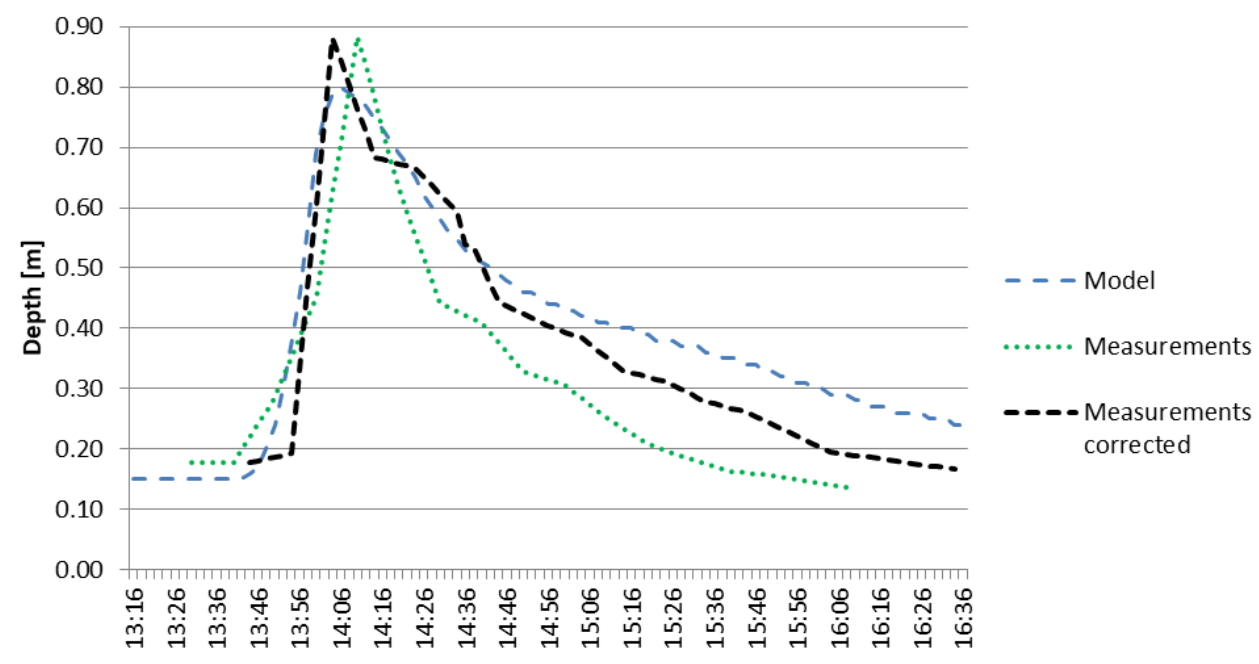

Fig. 3. Runoff depth in channel - 21.07.1999 - Measurement Point No. 6.

A consequence of the low quality of input data is especially the low compatibility of the duration time of simulated and registered outflow. Above all, the influence of the time of measurement was significant. The noticeable divergences in the occurrence of maximum depth are caused by the precision of the reading of the start value, which is the moment at which the device is activated upon replacing the tape. The error of the time component in the case of the limnigraph is nominally $30 \mathrm{~min} / 176 \mathrm{~h}$. As a consequence, the effect of moving the starting time of increased depth as well as the time of the occurrence of the minimum value is noticeable, especially in the case of the occurrence of the phenomenon in the end hours of a 7-day measurement period. 


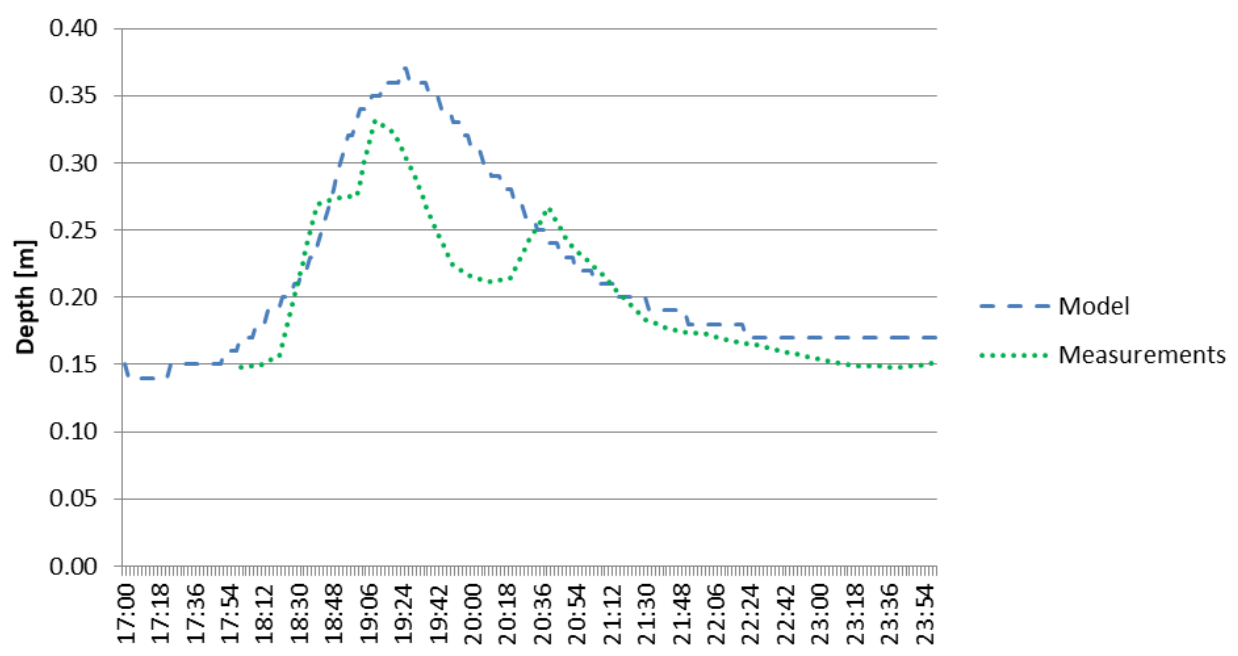

Fig. 4. Runoff depth in channel - 14.07.1999 - Measurement Point No. 6.

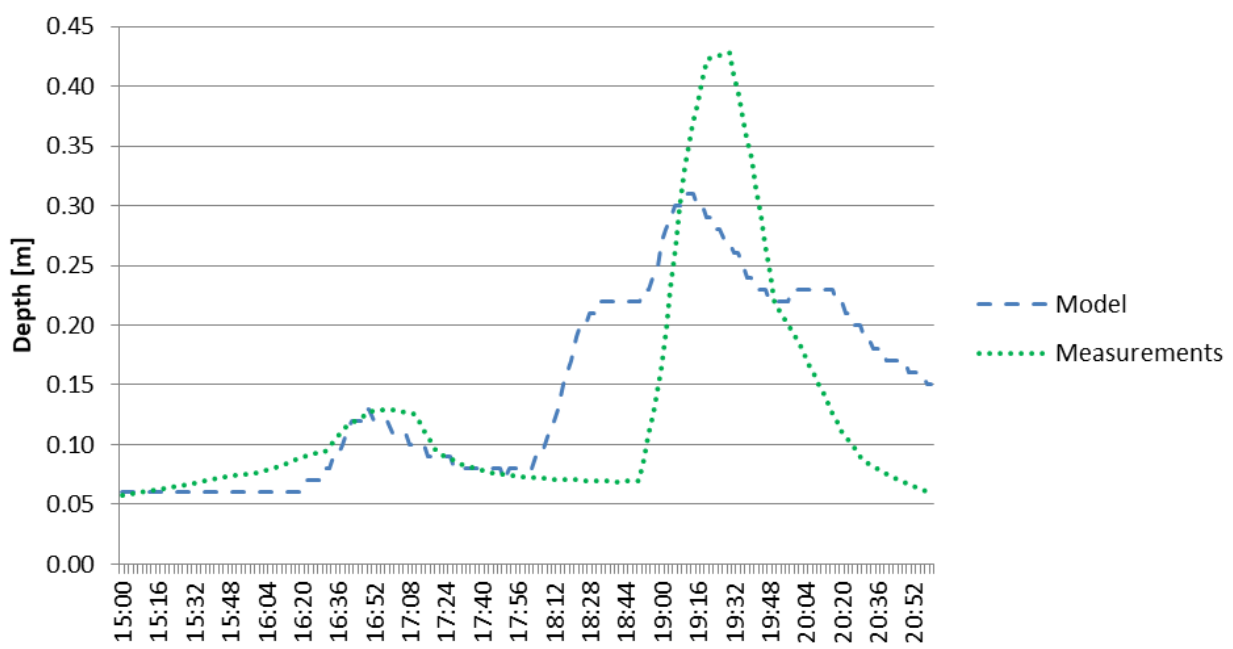

Fig. 5. Runoff depth in channel - 05.08.1999 - Measurement Point No. 7.

Following the analysis of limnigraph data, the possibility of the occurrence of a significant error in the period 21-28.07.1999 was confirmed at Point No. 6. After a phenomenon of a "catastrophic" nature on 1 July 1999, it was necessary to dissemble and carry out a major overhaul of the clock mechanism. The device was most likely installed incorrectly, and registration took place accounting for the 176/108 ratio, but with the opposite effect. The data were not registered in a 7-day cycle, but a ratio enabling the registration of even as many as 11 days on a tape designated for 7 days was obtained. In effect, too short of an outflow time increased by rainfall runoff was obtained.

In October 1999 and in the year 2000, similar effects were not observed. In the meantime, a further inspection of the equipment was carried out, but the company carrying out the service did not note down in the documentation the fact that the equipment was turned over for installation. Upon introducing a correction to the time of reading in relation to the total outflow volume, a relative error of under $10 \%$ was obtained in 6 cases, within the range of 10 to $25 \%$ - in 13 cases, and over $25 \%$ - in 4 cases. 


\section{Conclusion}

The possibility of the proper calibration of the model of the storm drainage and combined sewage system is strictly connected with the reliability of measurement data from the area of the catchment. Conclusions drawn from the realized field studies and implemented simulation models make it possible to state that the existing rain measurement network realized by the Institute of Meteorology and Water Management is too scattered; thus the necessity of building local networks of rain measurement stations enabling the rain coverage of only a part of the analysed catchment to be accounted for. In the current state, the model can be applied to assess the number of storm water overflow structure activations based on currently registered meteorological data. In the case of archival data, using one, not entirely representative rain gauge, the results obtained in the model do not guarantee proper results. As an effect, the analysis of the obtained results of simulations made it possible to formulate the following conclusions:

- in the case of cities of up to 100 thousand inhabitants, it is not possible to leave out the spatial variability of rainfall intensity;

- using the simulation model as a tool replacing the constant monitoring of runoff in storm water drains requires the maintenance of rain gauge monitoring with a density enabling the analysis of the scope of the occurrence of rain in the area covered by the analysed sewage system.

- the existing network for monitoring meteorological data used by the Institute of Meteorology and Water Management does not constitute a sufficient database for implementing and using local simulation models of storm water drainage networks.

- implementing simulation models ought to be preceded by an economic analysis of developing a simulation model and the costs of maintaining a network of rain gauges as compared to the maintenance of constant monitoring in storm water drains.

\section{References}

1. I. Nowogoński, J. Wira, Instal 9, 81 (2006)

2. I. Nowogoński, SR UZ EE 146, 32 (2012)

3. L. A. Rossman, Storm Water Management Model. User's Manual. Version 5 (US EPA, Cincinnati, 2010)

4. J. Temprano, Ó. Arango, J. Cagiao, J. Suárez, I. Tejero, Water SA. 32(1), 55 (2005)

5. A. Kotowski, The Basics of Safe Dimensioning of Site Drainage (Podstawy bezpiecznego wymiarowania odwodnień terenów) [in Polish] (Seidel-Przywecki, Warszawa, 2015) 